\title{
PENINGKATAN PEMAHAMAN MASYARAKAT TENTANG PELANGGARAN PEMILU KEPALA DAERAH DI KECAMATAN KERINCI KANAN KABUPATEN SIAK TAHUN 2020
}

\section{IMPROVEMENT OF COMMUNITY UNDERSTANDING ABOUT THE VIOLATION OF THE REGIONAL HEAD ELECTION IN KECAMATAN KANAN KANAN DISTRICT SIAK IN 2020}

\author{
Adrian Faridhi ${ }^{1,}$ Sudi Fahmi ${ }^{2,}$ Alexsander Yandra $^{3}$ \\ ${ }^{1}$ Fakultas Hukum Universitas Lancang Kuning Pekanabru \\ ${ }^{2}$ Fakultas Hukum Universitas Lancang Kuning Pekanbaru \\ ${ }^{3}$ Fakultas Ilmu Administrasi Universitas Lancang Kuning Pekanbaru \\ ${ }^{1}$ Email: adrian@unilak.ac.id
}

\begin{abstract}
Abstrak: Pelanggaran Pemilu/ Pemilihan Kepala Daerah sering terjadi pada masa pemilihan, mitra yang merupakan masyarakat Kecamatan Kerinci Kanan Kabupaten Siak Provinsi Riau akan melaksanakan pemilihan Bupati dan Wakil Bupati Siak pada tahun 2020, mitra merasa khawatir dengan jenis-jenis pelanggaran pemilu, mitra berharap mendapatkan informasi tentang jenis pelanggaran pemilu, pengabdian ini dilaksanakan dengan metode ceramah yang tetap mengedepankan protokol kesehatan, sebelum dan sesudah kegiatan peserta diberi angket untuk mengukur tingkat pemahaman terhadap materi. Hasil yang didapati terdapatnya peningkatan pemahaman masyarakat tentang jenis pelanggaran pemilu, lembaga yang mengawasi berupa Bawaslu, pelarangan ASN ikut serta dalam kampanye dan pelarangan praktik money politik.
\end{abstract}

Kata Kunci: Pelanggaran, Pemilihan Kepala Daerah, Siak

\begin{abstract}
Election violations / Regional Head Elections often occur during the election period, partners who are people of Kerinci Kanan Subdistrict, Siak Regency, Riau Province will carry out the election of the Regent and Deputy Regent of Siak in 2020, partners are worried about the types of election violations, partners hope to get information about types of election violations, this service is carried out with the ceramah method which still prioritizes health protocols, before and after the activity the participants are given a questionnaire to measure the level of understanding of the material. The results showed that there was an increase in public understanding of the types of election violations, the oversight institution in the form of Bawaslu, the prohibition of ASN from participating in campaigns and the prohibition of the practice of money politics.
\end{abstract}

Keywords: Violation, Regional Head Election, Siak

\section{PENDAHULUAN}

Amandemen UUD Tahun 1945 membawa perubahan yang besar terhadap ketatanegaraan Indonesia (Fahmi dkk, 2019) termasuk didalamnya berkenaan 
INTEGRITAS : Jurnal Pengabdian

Vol 5 No 1 Juli 2021

ISSN $2580-7978$ (cetak) ISSN 2615-0794 (online)

dengan pelaksanaan Pemilu, pesta demokrasi berupa Pemilihan Umum (Pemilu) baru usai, saatnya pesta demokrasi ditingkat lokal (daerah) akan diselenggarakan pada tahun 2020. Para kandidat calon kepala daerah bersiap-siap untuk maju mewujudkan cita-cita memajukan daerah, Pelaksanaan pemilihan kepala daerah (Pilkada) akan digelar pada tanggal 23 September 2020.

Menurut Ketua KPU Republik Indonesia, bahwa Pilkada tahun 2020 diselenggarakan di 270 (dua ratus tujuh puluh) daerah, dengan rincian 9 (sembilan) pemilihan gubernur dan wakil gubernur, 224 (dua ratus dua puluh empat) pemilihan bupati dan wakil bupati, serta 37 (tiga puluh tujuh) pemilihan walikota dan wakil walikota (https://m.detik.com/news/berita/d-4615384/pilkadaserentak-digelar-23-september-2020-ini-tahapannya diakses pada hari Rabu, tanggal 29 Januari 2020, Pukul 13.42 WIB). Untuk Provinsi Riau terdapat 9 (sembilan) kabupaten/kota di Provinsi Riau, yakni Rokan Hulu, Rokan Hilir, Siak, Dumai, Kuantan Singingi, Kepulauan Meranti, Bengkalis dan Dumai (https://m.halloriau.com/read.com/read-123548-2019-12-26-pilkada-serentak2020 -kpu-riau-segera-rekrut-ppk-danpps.html diakses pada hari Rabu, tanggal 29 Januari 2020, Pukul 13.55 WIB).

Berkaca dengan pelaksanaan Pemilu tahun 2019, banyak dijumpai pelanggaran-pelanggaran pemilu di Indonesia, oleh karena itu butuh cara maupun metode untuk mengantisipasi ataupun meminimalisir pelanggaran Pemilu (Pilkada) yang diselenggarakan tahun 2020. Pelanggaran berupa masyarakat yang tidak bisa memilih karena tidak terdaftar dalam DPT (Matua dkk, 2020), pelanggaran penggunaan alat peraga kampanye yang tidak sesuai aturan KPU (Faridhi, 2020). Bentuk sosialisasi dan pendidikan politik menjadi salah satu cara yang dapat ditempuh. KPU maupun Bawaslu sudah menjalankan peran tersebut, namun begitu luas cakupan wilayah dan keterbatasan personil menjadi hambatan tersendiri terhadap sosialisasi pelanggaran Pemilu.

Pemilukada memiliki posisi yang strategis dalam membangun demokrasi dalam masa transisi, agar Pemilukada tersebut memiliki daya ungkit yang besar dalam menciptakan demokrasi yang bermartabat yang penyelenggaraannya harus mengacu pada prinsip mandiri; jujur; adil; kepastian hukum; tertib penyelenggara 
Pemilu; kepentingan umum; keterbukaan; proporsionalitas; profesionalitas; akuntabilitas; efisiensi; dan efektifitas (Hoesein, 2010)

Aturan Pemilu tidak terlalu berbeda dengan aturan pelaksanaan Pilkada, aspek pelanggaran Pilkada menjadi sesuatu yang mesti diantisipasi, supaya pilkada yang menelan puluhan milyar tidak dirusak oleh praktek-praktek yang anti demokrasi, sehingga Pemilu berintegritas dan bermartabat dapat terwujud pada tahun 2020.

Permasalahan hukum pada masa Pemilu sangatlah banyak, oleh karena banyaknya yang menjadi permasalahan mitra membutuhkan informasi tentang pelanggaran Pemilu serta konsekuensi hukum yang menyertainya. Banyaknya jenis masalah hukum pemilu juga linear dengan banyaknya institusi yang terlibat dalam penanganannya. Setidaknya ada sembilan institusi yang terlibat, yaitu : (1) Dewan Kehormatan Penyelenggara Pemilu (DKPP), (2) Badan Pengawas Pemilu (Bawaslu); (3) Komisi Pemilihan Umum (KPU); (4) Kepolisian Negara; (5) Kejaksaan; (6) Pengadilan Tata Usaha Negara dan Pengadilan Tinggi Tata Usaha Negara; (7) Pengadilan Negeri dan Pengadilan Tinggi; (8) Mahkamah Agung; dan (9) Mahkamah Konstitusi. Belum lagi keterlibatan Komisi Penyiaran atau Dewan Pers untuk mengawasi pemberitaan dan iklan kampanye (Fahmi, 2015).

Menurut Oktafiani Catur Pratiwi bahwa Pelaksanaan Pemilu memiliki Problem prosedural terkait tahapan-tahapan dalam Pilkada mulai dari tahap persiapan, penetapan daftar pemilih, pendaftaran dan penetapan calon, kampanye, pencoblosan, penghitungan suara dan penetapan hasil sampai dengan pelantikan calon terpilih (Oktafiani Catur Pratiwi, 2017: 328) hal ini yang dapat menjadi perhatian masyarakat untuk ikut mengawasi pelaksanaan Pilkada.

Berdasarkan segi materinya, terdapat enam macam jenis pelanggaran Pemilu, yakni: Pelanggaran pidana pemilu (tindak pidana pemilu); Sengketa dalam tahapan/proses pemilu; Pelanggaran administrasi pemilu; Pelanggaran Kode Etik; Perselisihan hasil pemilu; dan Sengketa hukum lainnya (Polli, 2014). Mitra merupakan warga masyarakat yang akan mengikuti Pilkada yang akan diselenggarakan tahun 2020. Mitra sering mendapatkan informasi-informasi yang membingungkan tentang Pemilu. Media sosial maupun portal berita online yang 
INTEGRITAS : Jurnal Pengabdian

Vol 5 No 1 Juli 2021

ISSN 2580 - 7978 (cetak) ISSN 2615 - 0794 (online)

menguraikan fenomena-fenomena tentang pelaksanaan pemilu. Mitra bingung dan khawatir jika nanti dalam pelaksanaan Pilkada dapat terlibat dalam pelanggaran Pemilu.

Mitra meminta kepada Tim Pengabdian yang berasal dari Fakultas Hukum Unilak, untuk dapat menjelaskan tentang Pemilu serta jenis pelanggaran Pemilu (Pilkada) serta konsekuensi hukum yang menyertainya.

Mitra yang merupakan kelompok masyarakat yang bertempat tinggal di Kecamatan Kerinci Kanan Kabupaten Siak, oleh karena Kabupaten Siak merupakan salah satu Daerah yang menyelenggarakan Pilkada Tahun 2020.

\section{METODE}

Metode pelaksanaan merupakan solusi yang ditawarkan untuk mengatasi masalah yang dihadapi mitra. Sesuai dengan persoalan prioritas yang dihadapi mitra, yaitu masih kurang pahamnya mitra terhadap Pelanggaran Pemilu. Metode pendekatan yang ditawarkan untuk menyelesaikan persoalan mitra program yang telah disepakati bersama dalam kurun waktu realisasi program pengabdian kepada masyarakat adalah ceramah dan dialog dan bimbingan. Adapun prosedur kerja untuk mendukung metode yang ditawarkan adalah ceramah dilaksanakan dalam 1 (satu), sedangkan dialog dan bimbingan dilakukan dapat beberapa kali sesuai kebutuhan mitra selama masih dalam jangka waktu program. Partisipasi mitra dalam pengabdian kepada masyarakat ini adalah menyediakan tempat waktu pelaksanaan program serta menghadirkan anggota mitra.

Sebelum dimulainya ceramah maupun dialog, tim pengusul akan menyebarkan kertas angket. Setelah diselenggarakannya ceramah dan dialog, tim pengusul akan menyebarkan kembali kertas angket. Hal ini berguna untuk mengetahui peningkatan pemahaman peserta dalam kegiatan pengabdian masyarakat.

\section{HASIL DAN PEMBAHASAN}

\section{Hasil}

Kegiatan pengabdian kepada masyarakat ini telah dilaksanakan pada hari Rabu tanggal 28 Agustus 2020 bertempat di Gedung Pertemuan Kecamatan 
Kerinci Kanan Kabupaten Siak. Kegiatan ini dimulai Pukul 09.30 WIB sampai dengan Pukul 12.00 WIB. Jumlah peserta yang hadir dalam kegiatan ini sebanyak 25 (dua puluh lima) orang. Peserta yang hadir dalam pelaksanaan kegiatan ini adalah masyarakat dan perangkat kecamatan. Pelaksanaan kegiatan ini para peserta sangat antusias dalam mengikuti rangkaian acara hingga selesai, hal ini dapat dilihat saat sesi dialog tanya jawab antara peserta dengan narasumber. Masyarakat ternyata selama ini tidak mengetahui secara jelas tentang pelarangan pemilu ditambah dengan kondisi hari ini yang pandemi Covid 19.

\section{Pembahasan}

Evaluasi pengabdian kepada masyarakat ini dilakukan dengan cara membagikan kuisioner berupa pertanyaan yang harus dijawab oleh peserta yang berjumlah 25 orang. Pertanyaan yang dibuat dalam kuisioner adalah pemahaman tentang pelanggaran Pemilu dalam menghadapi Pemilihan Kepala Daerah Bupati dan Wakil Bupati Siak dapat dilihat sebagai berikut:

\section{Pertanyaan:}

1. Tahukah Anda jenis-jenis Pelanggaran Pemilu?

Tabel 1. Jawaban Responden Sebelum dan Sesudah Kegiatan

\begin{tabular}{clcccc}
\hline & \multicolumn{1}{c}{ Jawaban } & $\begin{array}{c}\text { Jumlah } \\
\text { Sebelum }\end{array}$ & $\begin{array}{c}\text { Jumlah } \\
(\boldsymbol{\%})\end{array}$ & $\begin{array}{c}\text { Jumlah } \\
\text { Sesudah }\end{array}$ & $\begin{array}{c}\text { Jumlah } \\
(\mathbf{\%})\end{array}$ \\
\hline A & $\begin{array}{l}\text { Pelanggaran administrasi, } \\
\text { pelanggaran etik dan dugaan } \\
\text { tindak pidana Pemilu }\end{array}$ & 5 & 20 & 24 & 96 \\
B & $\begin{array}{l}\text { Sengketa Hasil Pemilu } \\
\text { C }\end{array}$ & 4 & 16 & 0 & 0 \\
\hline & Tidak Tahu & 16 & 64 & 1 & 4 \\
\hline
\end{tabular}

Sumber : Hasil kuisioner, 28 Agustus 2020.

Data tabel di atas berdasarkan hasil jawaban dari peserta melalui kuisioner yang dibagikan sebelum kegiatan dan sesudah kegiatan pengabdian kepada masyarakat ini dilaksanakan. Sebelum kegiatan dilaksanakan peserta ditanya Tahukah Anda jenis-jenis Pelanggaran Pemilu? dari 25 orang peserta yang menjawab A (Pelanggaran administrasi, pelanggaran etik dan dugaan tindak pidana Pemilu), sebanyak 5 orang (20\%), yang menjawab B (Sengketa Hasil 
Pemilu), sebanyak 4 orang (16\%) dan menjawab C (Tidak Tahu), sebanyak 16 orang $(64 \%)$.

Jawaban peserta sesudah kegiatan pengabdian kepada masyarakat ini dilaksanakan yang menjawab A (Pelanggaran administrasi, pelanggaran etik dan dugaan tindak pidana Pemilu), yang memilih jawaban A jumlahnya 24 orang (96 $\%)$, yang menjawab B (Sengketa Hasil Pemilu), tidak ada yang menjawab (0 \%), dan yang menjawab C (Tidak Tahu), yang memilih jawaban $\mathrm{C}$ sebanyak 1 orang $(4 \%)$.

2. Siapa yang tugasi oleh peraturan perundang-undangan untuk mengawasi pelanggaran Pemilu?

Tabel 2. Jawaban Responden Sebelum dan Sesudah Kegiatan

\begin{tabular}{clcccc}
\hline & \multicolumn{1}{c}{ Jawaban } & $\begin{array}{c}\text { Jumlah } \\
\text { Sebelum }\end{array}$ & $\begin{array}{c}\text { Jumlah } \\
(\boldsymbol{\%})\end{array}$ & $\begin{array}{c}\text { Jumlah } \\
\text { Sesudah }\end{array}$ & $\begin{array}{c}\text { Jumlah } \\
(\boldsymbol{\%})\end{array}$ \\
\hline A & Dewan Kehormatan & 2 & 8 & 0 & 0 \\
\multirow{2}{*}{ B } & Penyelenggara Pemilu & & & & 12 \\
Comisi Pemilihan Umum & Badan Pengawas Pemilu & 14 & 56 & 22 & 88 \\
\hline \multicolumn{1}{c}{ Total } & 25 & 100 & 25 & 100 \\
\hline
\end{tabular}

Sumber : Hasil kuisioner, 28 Agustus 2020.

Data tabel di atas berdasarkan hasil jawaban dari peserta melalui kuisioner yang dibagikan sebelum kegiatan dan sesudah kegiatan pengabdian kepada masyarakat ini dilaksanakan. Sebelum kegiatan dilaksanakan peserta ditanya Siapa yang ditugasi oleh peraturan perundang-undangan untuk mengawasi pelanggaran Pemilu? dari 25 orang peserta yang menjawab A (Dewan Kehormatan Penyelenggara Pemilu), sebanyak 2 orang (8\%), yang menjawab B (Komisi Pemilihan Umum), sebanyak 9 orang (36\%) dan menjawab C (Badan Pengawas Pemilu), sebanyak 14 orang (56\%).

Jawaban peserta sesudah kegiatan pengabdian kepada masyarakat ini dilaksanakan yang menjawab A (Dewan Kehoramatan Penyelenggara Pemilu), yang memilih jawaban A tidak ada yang memilih (0\%), yang menjawab B (Komisi Pemilihan Umum), sebanyak 3 orang (12\%), dan yang menjawab C (Badan Pengawas Pemilu), yang memilih jawaban C sebanyak 22 orang (88 \%). 
INTEGRITAS : Jurnal Pengabdian

Vol 5 No 1 Juli 2021

ISSN 2580-7978 (cetak) ISSN 2615-0794 (online)

3. Apakah Aparatur Sipil Negara boleh ikut dalam pelaksanaan kampanye?

Tabel 3. Jawaban Responden Sebelum dan Sesudah Kegiatan

\begin{tabular}{|c|c|c|c|c|c|}
\hline & Jawaban & $\begin{array}{c}\text { Jumlah } \\
\text { Sebelum }\end{array}$ & $\begin{array}{c}\text { Jumlah } \\
(\%)\end{array}$ & $\begin{array}{c}\text { Jumlah } \\
\text { Sesudah }\end{array}$ & $\begin{array}{c}\text { Jumlah } \\
(\%)\end{array}$ \\
\hline A & Boleh & 10 & 40 & 0 & 0 \\
\hline B & Tidak & 10 & 40 & 24 & 96 \\
\hline $\mathrm{C}$ & Ragu-ragu & 5 & 20 & 1 & 4 \\
\hline & Total & 25 & 100 & 25 & 100 \\
\hline
\end{tabular}

Sumber : Hasil kuisioner, 28 Agustus 2020.

Data tabel di atas berdasarkan hasil jawaban dari peserta melalui kuisioner yang dibagikan sebelum kegiatan dan sesudah kegiatan pengabdian kepada masyarakat ini dilaksanakan. Sebelum kegiatan dilaksanakan peserta ditanya Apakah Aparatur Sipil Negara boleh ikut dalam pelaksanaan kampanye? dari 25 orang peserta yang menjawab A (Boleh), sebanyak 10 orang (40\%), yang menjawab B (Tidak), sebanyak 10 orang (40\%) dan menjawab C (Ragu-ragu), sebanyak 5 orang $(20 \%)$.

Jawaban peserta sesudah kegiatan pengabdian kepada masyarakat ini dilaksanakan yang menjawab A (Boleh), tidak ada yang memilih jawaban A (0 \%), yang menjawab B (Tidak), sebanyak 24 orang (96\%), dan yang menjawab $\mathrm{C}$ (Ragu-ragu), yang memilih jawaban $\mathrm{C}$ sebanyak 1 orang (4\%).

4. Money Politik masuk dalam jenis pelanggaran Pemilu?

Tabel 4. Jawaban Responden Sebelum dan Sesudah Kegiatan

\begin{tabular}{clcccc}
\hline & Jawaban & $\begin{array}{c}\text { Jumlah } \\
\text { Sebelum }\end{array}$ & $\begin{array}{c}\text { Jumlah } \\
(\boldsymbol{\%})\end{array}$ & $\begin{array}{c}\text { Jumlah } \\
\text { Sesudah }\end{array}$ & $\begin{array}{c}\text { Jumlah } \\
(\%)\end{array}$ \\
\hline A & Pelanggaran Administrasi & 5 & 20 & 0 & 0 \\
B & Tindak Pidana Pemilu & 15 & 60 & 25 & 100 \\
C & Sengketa Hasil Pemilu & 5 & 20 & 0 & 0 \\
\hline & Total & 25 & 100 & 25 & 100 \\
\hline
\end{tabular}

Sumber : Hasil kuisioner, 28 Agustus 2020.

Data tabel di atas berdasarkan hasil jawaban dari peserta melalui kuisioner yang dibagikan sebelum kegiatan dan sesudah kegiatan pengabdian kepada masyarakat ini dilaksanakan. Sebelum kegiatan dilaksanakan peserta ditanya Money Politik masuk dalam jenis pelanggaran Pemilu? dari 25 orang peserta yang menjawab A (Pelanggaran Administrasi), sebanyak 5 orang (20 \%), yang 
menjawab B (Tindak Pidana Pemilu), sebanyak 15 orang (60\%) dan menjawab C (Sengketa Hasil Pemilu), sebanyak 5 orang (20\%).

Jawaban peserta sesudah kegiatan pengabdian kepada masyarakat ini dilaksanakan yang menjawab A (Pelanggaran Administrasi), tidak ada yang memilih jawaban A (0\%), yang menjawab B (Tindak Pidana Pemilu), sebanyak 25 orang (100\%), dan yang menjawab C (Sengketa Hasil Pemilu), tidak ada yang memilih jawaban $\mathrm{C}(0 \%)$.

\section{KESIMPULAN}

Pelaksanaan pengabdian kepada masyarakat yang dilaksanakan di Kecamatan Kerinci Kanan Kabupaten Siak berjalan dengan lancar, masyarakat mendapatkan peningkatan pemahaman akan bentuk dan jenis pelanggaran Pemilu/Pilkada.

\section{UCAPAN TERIMA KASIH}

Penyampaian ucapan terima kasih kepada Lembaga Penelitian dan Pengabdian Kepada Masyarakat Universitas Lancang Kuning dan Pemerintah Kecamatan Kerinci Kanan Kabupaten Siak Provinsi Riau atas terselenggaranya kegiatan pengabdian ini.

\section{DAFTAR PUSTAKA}

Fahmi.K. (2015). Sistem Penangganan Tindak Pidana Pemilu. Jurnal Konstitusi, 12(2). 265-283.

Fahmi.S., Faridhi.A., Hasnati. (2019). The development of Indonesian State Concerns before and After Amendment to the 1945 Constitution. International Journal of Innovation, Creativity and Change. 10(5). 242256.

Faridhi. A. (2020). The Violation of Campaign Props Installation in 2019 Election in Pekanbaru. Journal of Election and Leadership (JOELS). 1(1). 29-36.

Hoesein. Z.A. (2010). Pemilu Kepala Daerah dalam Transisi Demokrasi. Jurnal Konstitusi, 7(6). 1-23.

Matua. S, Faridhi. A, Fahmi.S, Yandra.A. (2020). Problems of Voting Rights in Elections in Siak Regency, Riau Province. Journal of Election and Leadership (JOELS). 1(2). 6-12.

Polli.F. (2014). Penyelesaian Pelanggaran Pemilihan Kepala Daerah dan Wakil Kepala Daerah (Pemilukada) oleh Komisi Pemilihan Umum Daerah (KPUD). Lex et Societatis. II(6). 113-123. 
INTEGRITAS : Jurnal Pengabdian

Vol 5 No 1 Juli 2021

ISSN 2580 - 7978 (cetak) ISSN 2615 - 0794 (online)

Pratiwi.O.C. (2017). Menjaga Kualitas Pemilu Yang Demokratis. Jurnal Bawaslu.3(3). 323-333.

Undang-Undang Dasar Negara Republik Indonesia Tahun 1945.

Undang-Undang Nomor 7 Tahun 2017 tentang Pemilihan Umum.

\section{Portal Berita}

(https://m.detik.com/news/berita/d-4615384/pilkada-serentak-digelar-23september-2020-ini-tahapannya diakses pada hari Rabu,tanggal 29 Januari 2020, Pukul 13.42 WIB).

(https://m.halloriau.com/read.com/read-123548-2019-12-26-pilkada-serentak2020-kpu-riau-segera-rekrut-ppk-danpps.html diakses pada hari Rabu, tanggal 29 Januari 2020, Pukul 13.55 WIB). 